\title{
El archivo como pilar del ciclo de vida del documento electrónico. Experiencia de Informática El Corte Inglés
}

Carlota Tortosa Gil

INFORMÁTICA EL CORTE INGLÉS

PRoYectos DE ARCHIVO

\section{Resumen}

Se presenta la experiencia de Informática El Corte Inglés en proyectos de desarrollo e implantación de sistemas de gestión de documentos en fase de archivo, con su aplicación ArchiDOC y su evolución, para el Gobierno de Canarias, en su sistema SPERIA, siguiendo la norma OAISISO 14721.

Palabras clave: Gobierno de Canarias; SPERIA; ArchiDOC; Modelo OAIS; ISO 14721; Archivo electrónico único

Cita recomendada: Tortosa Gil, C. (2018). El archivo como pilar del ciclo de vida del documento electrónico. Experiencia de Informática El Corte Inglés. En El archivo electrónico en la administración digital: 23 Jornadas de Archivos Universitarios, 21-23 de junio de 2017, A Coruña (pp. 113-120).

DOI capítulo: https://doi.org/10.17979/spudc.9788497496803.113

DOI libro: https://doi.org/10.17979/spudc.9788497496803 
Las necesidades funcionales que son exigibles a un sistema de gestión de documentos varían en función de la fase del ciclo de vida en que estos se encuentran. De este modo, un sistema de gestión de documentos en fase de tramitación dispondrá de funcionalidades que, en muchos casos, serán muy distintas a las de un sistema de gestión de documentos en fase de archivo.

De forma muy resumida, funcionalidades como la modificación y el borrado de documentos deben permitirse en un sistema de gestión de documentos de trámite y prohibirse en un sistema de gestión de documentos en fase de archivo. Otras funcionalidades como normas de conservación, mantenimiento del contexto y gestión de estructura de clasificación y almacenamiento, solo son obligatorias en los sistemas de gestión de documentos en fase de archivo (por ejemplo, Moreq 2010).

Para garantizar la transparencia y rendición de cuentas del e-gobierno, los documentos electrónicos deben ser auténticos, íntegros y accesibles a largo plazo. Para ello deben contar con pruebas de validación electrónica: firma, sello de tiempo y metadatos.

Los sistemas de gestión de documentos electrónicos deben tener presente las distintas formas en que estos pueden ser creados al:

- ser presentados por los ciudadanos en las oficinas de registro;

- ser producidos por las administraciones por la automatización de la gestión; o

- ser digitalizados: imágenes de documentos analógicos como sustitución de los originales mediante digitalización certificada.

Hay todo un conjunto de normas y estándares internacionales, comúnmente aceptados, que deben cumplir los sistemas que se desarrollan para la gestión de documentos electrónicos. Los más 
destacados -que Informática El Corte Inglés ha incorporado en el desarrollo de su aplicación ArchiDOC-son:

- UNE-ISO 15489: Gestión de documentos.

- MoReq 2010: Modelo de Requisitos para la gestión de documentos electrónicos de. archivo.

- $\operatorname{ISAD}(\mathrm{G})$ : Norma Internacional General de Descripción Archivística.

- ISAAR-CPF: Norma Internacional sobre los Registros de Autoridad de Archivos relativos a Instituciones, Personas y Familias.

- EAD: Descripción Archivística Codificada.

- UNE-ISO 19005: Gestión de documentos. Formato de fichero de documento electrónico para la conservación a largo plazo.

- UNE-ISO 30300: Sistemas de gestión para los documentos. Fundamentos y vocabulario.

- UNE-EN ISO/IEC 27001: Tecnología de la información. Técnicas de seguridad. Sistemas de Gestión de la Seguridad de la Información. Requisitos.

- UNE-ISO 23081: Procesos de gestión de documentos. Metadatos para la gestión de documentos.

Actualmente, y para adaptarse a la Ley 39/2015, de 1 de octubre, del Procedimiento Administrativo Común de las Administraciones Públicas, Informática El Corte Inglés, por encargo del Gobierno de Canarias, está adaptando su sistema SPERIA (basado en la aplicación ArchiDOC) para cumplir el modelo Open Archival Information System (OAIS) que se traspuso en la norma ISO 14721. 
Para facilitar la captura de expedientes electrónicos al sistema de archivo, se van a desarrollar los siguientes componentes:

- Servicio web para crear el índice electrónico de un expediente. Está diseñado para dar servicio a aplicaciones tramitadoras que no dispongan de esta funcionalidad, imprescindible para la gestión de expedientes electrónicos. Este servicio validará de forma automática los metadatos del expediente electrónico y de sus documentos electrónicos, así como los propios documentos electrónicos (existencia, hash y firma correcta), y firmará el índice electrónico creado si la aplicación de tramitación así lo solicita.

- Servicio web para la creación de los Paquetes de Información de Transferencia (PIT). El proceso de captura de la norma OAIS implica que las aplicaciones tramitadoras envíen a la de archivo los expedientes electrónicos en forma de PIT. Este servicio web está diseñado para atender a aquellas aplicaciones que no dispongan de esta funcionalidad. Este validará de forma automática:

- el expediente finalizado con todos sus documentos electrónicos firmados y metadatos;

- el formato de los documentos electrónicos. Se contrastarán estos formatos con una relación de formatos aceptados/rechazados y se suministrará un servicio de conversión de formatos; $y$

- la existencia del índice electrónico, la validez de su firma y sus metadatos.

Una vez superadas estas validaciones, compondrá el XML en formato METS (Metadata Encoding and Transmission Standard), generará y almacenará el PIT, y lo incorporará a su relación de entrega (serie y órgano productor). 
El resultado de estas acciones será comunicado al sistema tramitador desde el que se le invocó, ofreciéndole así mismo la posibilidad de consulta de estado de generación de sus PIT.

- El proceso de captura a desarrollar, según la norma OAIS, mediante el que se incorporan los PIT al sistema de archivo, se compondrá de:

- Cotejo manual por parte de los archiveros: verificación de los metadatos del expediente electrónico, apertura de sus documentos electrónicos y verificación de sus metadatos, revisión del índice electrónico y aceptación o rechazo del PIT.

- Conversión de los PIT a PIA (Paquete de Información de Archivo) e indexación de metadatos en el sistema de información. Para ello se creará un nuevo XML, al que se añadirán los metadatos necesarios para gestionar, preservar, acceder y representar los documentos a lo largo del tiempo, incluyendo los documentos electrónicos correspondientes. Se firmará con el sello electrónico del órgano responsable y se almacenará en el sistema de gestión de documentos electrónicos en fase de archivo.

- Finalización, de forma manual por los archiveros, de la relación de entrega una vez finalizado el cotejo de todos sus PIT.

Asimismo, se desarrollará la funcionalidad de creación de los Paquetes de Información de Consulta (PIC) para permitir la consulta de expedientes electrónicos de archivo a productores e interesados. Los PIC se crearán como consecuencia de una solicitud de consulta, que podrá ser revisada por los archiveros en aquellos casos en los que el solicitante no sea el órgano productor del expediente. En estas situaciones será el personal del archivo el que indique los documentos y metadatos que van a componer el PIC. Además, se creará y firmará el índice electrónico correspondiente al PIC (Figura 1). 


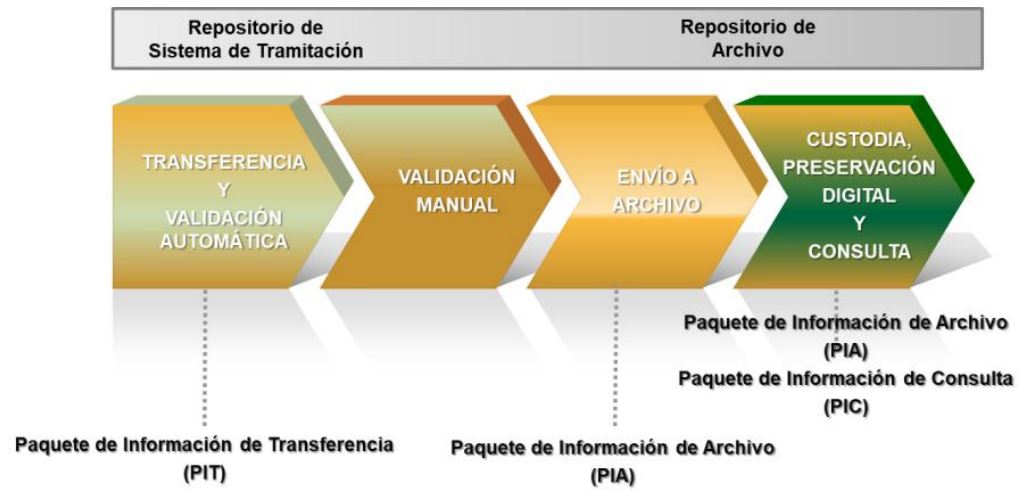

Figura 1. Modelo operativo que ArchiDOC va a seguir en su adaptación para el sistema SPERIA del Gobierno de Canarias.

En el proceso de preservación digital, el sistema de gestión de documentos electrónicos en fase de archivo se dotará de herramientas de administración de formatos, mediante las que se pueda gestionar la obsolescencia de estos con la conversión de los documentos a nuevas versiones, garantizando de este modo su acceso a largo plazo. Así mismo, se dispondrá de mecanismos de comunicación con los usuarios del sistema de gestión de archivo. Estos les informarán de las tareas a realizar como consecuencia de las políticas de eliminación de documentos (expurgo), de obsolescencia de formatos (cambio de formato) y de caducidad de firma (refirmado, re-sellado); así, el usuario podrá priorizar y programar las tareas a realizar automáticamente por el sistema. 


\section{Bibliografía}

Asociación Española de Normalización y Certificación. (2015). UNE-ISO 14721 Sistemas de transferencia de datos e información espaciales. Sistema abierto de información de archivo (OAIS). Modelo de referencia. Recuperado de <http://www.aenor.es>.

CCSDS Secretariat (2012). Reference Model for an Open Archival Information System (OAIS). Recommended practice (CCSDS 650.0-M-2). Magenta book. Recuperado de <https://public.ccsds.org/pubs/650x0m2.pdf >.

Dirección de Tecnologías de la Información y las Comunicaciones. (2016). Esquema de Metadatos para la Gestión del Documento Electrónico (eEMGDE) versión 2.0: documentación complementaria a la Norma Técnica de Política de gestión de documentos electrónicos. Recuperado de $<\mathrm{http}$ ://administracionelectronica.gob.es>.

Dirección de Tecnologías de la Información y las Comunicaciones. (2016). Guía de aplicación de la Norma Técnica de Interoperabilidad de Documento Electrónico. Recuperado de <http://administracionelectronica. gob.es>.

DLM Forum. (2010). MoReq2010 Specification v1.1. Recuperado de <http://www.moreq.info/specification>.

Ministerio de Hacienda y Administraciones Públicas. (2016). Política de gestión de documentos electrónicos MINHAP (2. ${ }^{a}$ ed.). Recuperado de $<\mathrm{http} / / /$ www.minhafp.gob.es>.

Orden de 23 de febrero de 2015, por la que se aprueba la Política de gestión de documentos electrónicos y archivo electrónico de la Administración Pública de la Comunidad Autónoma de Canarias. Canarias. Boletín Oficial de Canarias, 27 de febrero de 2015, núm. 40, pp. 4309-4328. Recuperado de <http://www.gobiernodecanarias.org/boc/2015/040/001.html>. 
Orden de 21 de noviembre de 2013, por la que se aprueba el esquema de metadatos en el ámbito de la administración electrónica de la Administración Pública de la Comunidad Autónoma de Canarias. Canarias. Boletín Oficial de Canarias, 29 de noviembre de 2013, núm. 40, pp. 43094328. Recuperado de <http://www.gobiernodecanarias.org/boc/2013/231/ 001.html>. 